\title{
Silicon carbide defects and luminescence centers in current heated $6 \mathrm{H}-\mathrm{SiC}$
}

\author{
S.W. Lee ${ }^{1}$, S.I. Vlaskina ${ }^{2,3}$, V.I. Vlaskin ${ }^{4}$, I.V. Zaharchenko ${ }^{4}$, V.A. Gubanov ${ }^{4}$, G.N. Mishinova ${ }^{4}$, \\ G.S. Svechnikov ${ }^{3}$, V.E. Rodionov ${ }^{3}$, and S.A. Podlasov ${ }^{5}$ \\ ${ }^{1}$ Department of Physics, Dongguk University, Pildong 3-26, Chung-ku, Seoul 100-715, Korea \\ ${ }^{2}$ Dong Seoul College, 461-714, 423, Bokjung-Dong, Sungnam-city, Kyonggi-do, Korea \\ Tel.: 82 (031) 7202141; fax: 82(031)202261; e-mail: svitlana@dsc.ac.kr \\ ${ }^{3}$ V. Lashkaryov Institute of Semiconductor Physics, National Academy of Science of Ukraine, \\ 45, prospect Nauky, 03028 Kyiv, Ukraine \\ ${ }^{4}$ Taras Shevchenko Kyiv National University, 64, Volodymyrs'ka str., 01033 Kyiv, Ukraine \\ ${ }^{5}$ National Technical University of Ukraine "Kyiv Polytechnic Institute", \\ 37, prospect Peremogy, 03056 Kyiv, Ukraine
}

\begin{abstract}
At room temperature yellow photoluminescence with a broad peak of $2.13 \mathrm{eV}$ is a well-known feature of boron-doped $6 \mathrm{H}-\mathrm{SiC}$. Usually yellow luminescence is regarded as recombination involving both the boron-related deep acceptor and donor level. But the nature of the deep level has not been clearly understood yet. We annealed $6 \mathrm{H}-\mathrm{SiC}$ substrates by current in vacuum without boron injection at the temperature of 1350 and $1500{ }^{\circ} \mathrm{C}$. We received red and yellow luminescence in PL spectrum for the heated $6 \mathrm{H}-\mathrm{SiC}$. The luminescence was regarded as donor-acceptor pair recombination involving the deep aluminum acceptor related to the adjacent carbon vacancies and nitrogen donor or the formation of quantum well like regions of $3 \mathrm{C}-\mathrm{SiC}$ in $6 \mathrm{H}-\mathrm{SiC}$ matrix.
\end{abstract}

Keywords: luminescence center, silicon carbide, stacking faults, donor acceptor pair.

Manuscript received 03.09.09; accepted for publication 22.10.09; published online 04.12.09.

\section{Introduction}

Silicon carbide has the unique properties proven to reduce energy losses in high-power, high frequency, high temperature and harsh-environment electronics. The principle markets for silicon carbide include solar power, computing, and military-aerospace applications. $\mathrm{SiC}$ electronics is expected to revolutionize the design of hybrid electric vehicles making them more fuel efficient.

Silicon carbide is a material of the future application owing to its possibility of being used as a material for high power, high temperature, and high frequency devices working without degradation. But over the last years the degradation has been demonstrated by different investigators during the longterm operation in high power $\mathrm{SiC}$ devices [1]. The degradation was observed in the diodes formed by diffusion, ion implantation and epitaxial growth. The degradation was caused by the generation of defects in the device active region. Using site-specific plan-view transmission electron microscopy (TEM) and light- emission imaging (LEI), defects were identified as stacking faults (SFs) formed during forward biasing of $4 \mathrm{H}-\mathrm{SiC}$ pin-diodes. Yellow electro-luminescence radiation $(1.8-2.2 \mathrm{eV})$ was observed during such defects propagation.

Yellow luminescence usually appears together with deep levels created by impurities, especially boron [2-4].

Boron, aluminum, gallium are used for fabrication of p-type doping in SiC-based devices. These impurities create energetically shallow levels in the band gap. Especially boron makes the deep level and yellow luminescence usually appears together with that levels in the spectra range from 2.03 to $2.13 \mathrm{eV}[5,6]$. The authors think that the luminescent deep center is related with boron, which creates a certain system with vacancies [3, 5-9]. Acceptor or donor property of such a system depends on $\mathrm{Si}$ or $\mathrm{C}$ position of the boron atom. The reason for such suggestion comes from the observation of yellow luminescence in boron-doped $\mathrm{SiC}$ by diffusion, or by implantation, or during crystal or epilayers growth. The ionization energy levels for the 
deep boron center called " $\mathrm{D}$-center" in $6 \mathrm{H}-\mathrm{SiC}$ are $(0.63$ and $0.71 \mathrm{eV})$ [7] or $(0.58$ and $0.63 \mathrm{eV})$ [8] or $0.74 \mathrm{eV}$ [9]. The ionization energy for deep boron center in $3 \mathrm{C}$ $\mathrm{SiC}$ is $0.748 \mathrm{eV}[10]$.

But some authors could not generate the D-center in $\mathrm{B}$-implanted $6 \mathrm{H}-\mathrm{SiC}$ when it was annealed under the temperature of $1200{ }^{\circ} \mathrm{C}$ [3]. Others observed an increase in the intensity of yellow luminescence after fast neutron irradiation [10].

In all cases yellow luminescence appears after the heat treatment. Besides boron, intrinsic and extrinsic defect centers are present in $\mathrm{SiC}$ crystals giving a rise to the deep levels in the band gap [11].The defects related to the deep levels in SiC so far are mostly known to be due to the transition metals $(\mathrm{V}, \mathrm{Ti})$. These deep levels may act either as the trapping centers for electrons or holes or as the recombination centers limiting the lifetime of the free charge carrier. Chemical nature and structure and acceptor or donor characteristics of deep levels and luminescence transitions are still an open question. The investigation of the process of the vacancies creation in $\mathrm{SiC}$ and their role in the doping processes are very important. We tried to make defects by resistive self-heating of $6 \mathrm{H}-\mathrm{SiC}$ in vacuum instead of annealing with graphite crucible, in which some boron and transition metal impurities could exist. Photoluminescence (PL) spectra of the heated $6 \mathrm{H}-\mathrm{SiC}$ crystals were investigated.

\section{Experiment}

The $n$-type $6 \mathrm{H}-\mathrm{SiC}$ substrate $\left(N_{D}-N_{A}=1.4 \times 10^{18} \mathrm{~cm}^{-3}\right.$, (0001), TO298-19, CREE Research, Inc.) grown by modified Lely method was heated in vacuum. The vacuum chamber was made by SUS-304. We connected the electrode with the clamps made from molybdenum to both sides of the sample of $5 \times 7 \mathrm{~mm}$ size. The distance between the electrode clamps was $5 \mathrm{~mm}$ and we increased the AC voltage up to $35 \mathrm{~V}$. Temperature was determined by optical pyrometer (M90-H, MIKRON Instrument Co., Inc, USA). The heating time was $90 \mathrm{~min}$ at the temperature of $1350{ }^{\circ} \mathrm{C}$ and $60 \mathrm{~min}$ at $1500{ }^{\circ} \mathrm{C}$. Temperature fluctuation was $\pm 10^{\circ} \mathrm{C}$. Vacuum was $8 \times 10^{-6}$ Torr through a diffusion pump. After heating black carbon layers appeared on the surface. These carbon layers could indicate the formation of vacancies at the carbon sites in the crystal. The substrates were polished with a diamond compound in order to remove the carbon layers. Not heated crystal, which was the other part of the same substrate, was polished using the same method. We measured PL with the excitation wavelength of $337.1 \mathrm{~nm}$ at 77 and $4.2 \mathrm{~K}$.

\section{Results and discussions}

Figure 1 shows the PL spectrum of the not heated $6 \mathrm{H}-$ $\mathrm{SiC}$. The peak near $2.7 \mathrm{eV}$ is usually attributed to the nitrogen donor-aluminum acceptor pair (DAP) recombination luminescence. The peak is composed of several peaks that are dependent on hexagonal-like and cubic-like sites of impurities. The entire PL configuration is in agreement with the work for the aluminum and nitrogen doped $6 \mathrm{H}-\mathrm{SiC}[6]$. Below $2.3 \mathrm{eV}$ there were no signals related with other transitions.

After the $n$-type $6 \mathrm{H}$-SiC substrates were heated by current for $60 \mathrm{~min}$ at $1500{ }^{\circ} \mathrm{C}$. PL spectrum of the sample in Fig. 2a showed different shape compared with the original one. The DAP recombination luminescence remained. But the new bands near 1.95 and $2.1 \mathrm{eV}$ were observed. These bands were also detected for the sample heated at $1350{ }^{\circ} \mathrm{C}$ in Fig. $2 \mathrm{~b}$.

At $77 \mathrm{~K}$ and room temperature yellow photoluminescence with a broad peak of $2.03-2.13 \mathrm{eV}$ is a well-known feature of boron-doped $6 \mathrm{H}-\mathrm{SiC}$. Usually yellow luminescence is regarded as recombination involving the deep acceptor (D-center) and the donor levels or free electron $[5,6]$. In case of our results the luminescence is similar with the D-center, but boron could not participate in this luminescence because in the

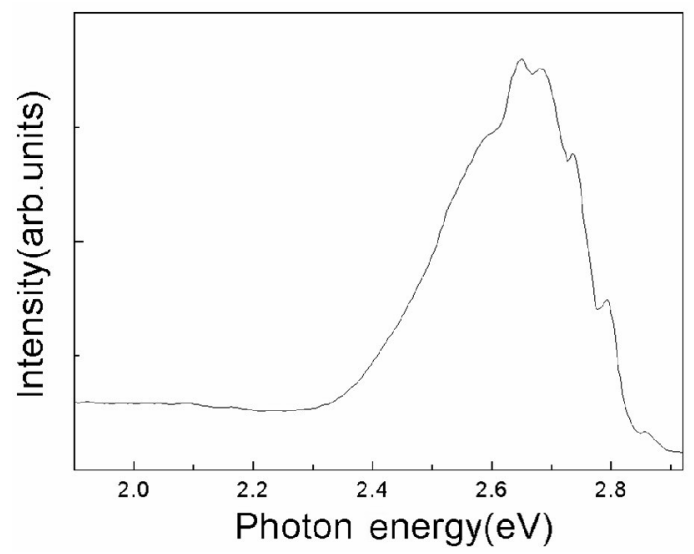

Fig. 1. The PL spectrum of the original (not heated) $6 \mathrm{H}-$ $\mathrm{SiC}(77 \mathrm{~K})$.

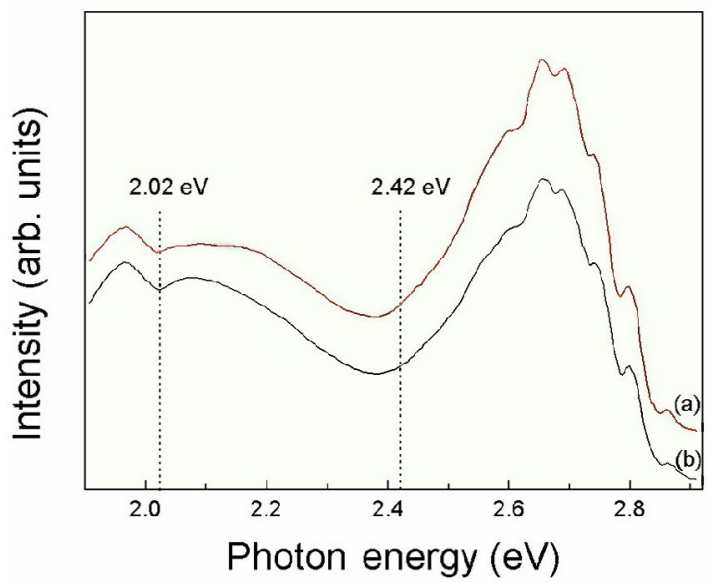

Fig. 2. The PL spectra $(77 \mathrm{~K})$ of the $6 \mathrm{H}-\mathrm{SiC}$ heated at the temperature of $1500{ }^{\circ} \mathrm{C}$ for $60 \mathrm{~min}$ (a) and $1350{ }^{\circ} \mathrm{C}$ for $90 \mathrm{~min}$ (b). The onset points are 2.02 and $2.42 \mathrm{eV}$ for the red and yellow luminescence, respectively. 


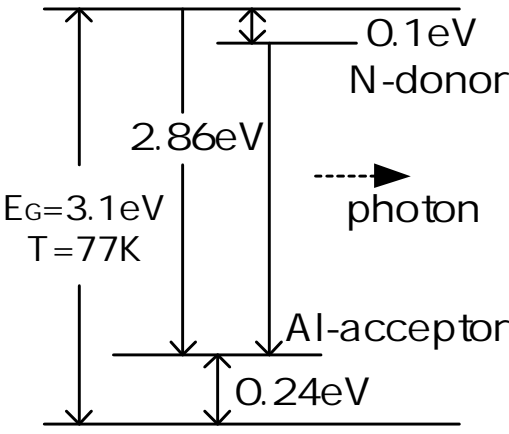

$a$

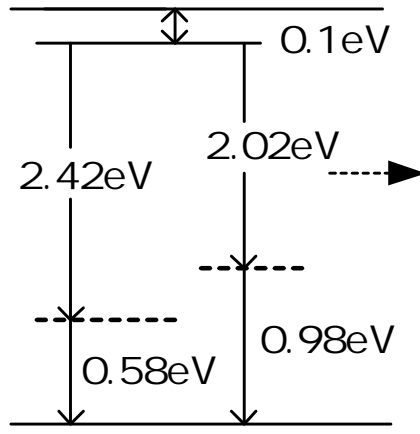

$b$

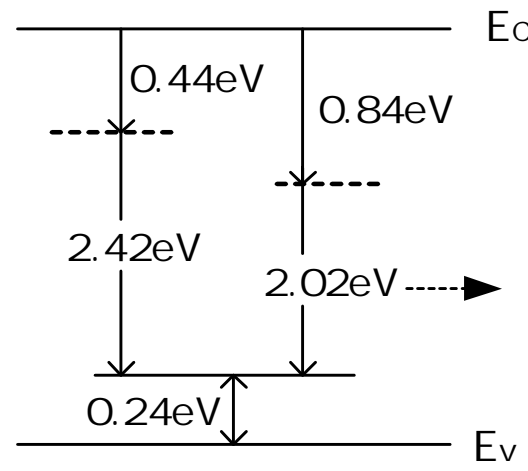

c

Fig. 3. Recombination models for the luminescence of (a) shallow donor-shallow donor, (b) deep donor-shallow acceptor, and (c) deep acceptor-shallow donor in $6 \mathrm{H}-\mathrm{SiC}$.

original crystal boron didn't exist. We were able to calculate the levels of the luminescence center according to two kinds of assumption of the deep donor and the deep acceptor. From the exciton band gap of $E_{g}=$ $3.023 \mathrm{eV}$ at $6 \mathrm{~K}$ [12] and the free exciton binding energy of $E_{X}=0.078 \mathrm{eV}$ [13] we estimated the band gap energy of $E_{g}=3.1 \mathrm{eV}$ at $77 \mathrm{~K}$ assuming that the variation of $E_{g}$ is small in the temperature range from 6 to $77 \mathrm{~K}$. The ionization energy of the nitrogen donor can be from 0.07 to $0.15 \mathrm{eV}$ and the aluminum acceptor 0.239 and $0.249 \mathrm{eV}$ depending on the lattice site, which is occupied by the nitrogen or aluminum(a hexagonallike or a cubic-like site), and on the concentration of nitrogen [6]. If we choose the band gap energy of $3.1 \mathrm{eV}$ at $77 \mathrm{~K}, 0.1 \mathrm{eV}$ of nitrogen level, and $0.24 \mathrm{eV}$ of aluminum in $6 \mathrm{H}-\mathrm{SiC}$ (Fig. 3) and extrapolated equation [14], $h v=E_{g}-\left(E_{D}+E_{A}\right)\left(E_{D}-\right.$ donor binding energy, $E_{A}$ - acceptor binding energy), the PL spectra in Fig. 2 could be explained. In case of the deep acceptor the levels were about 0.58 and $0.98 \mathrm{eV}$ (Fig. 3b). In case of the deep donor the levels were about 0.44 and $0.84 \mathrm{eV}$ (Fig. 3c).

In relation to other papers we could interpret our results as a deep Al center. Baranov et al. [15] observed the deep Al by direct electron paramagnetic resonance (EPR) measurement and it was about $0.1 \mathrm{eV}$ more shallow than the deep boron level. They suggested the model of the deep Al center as a group: the elementvacancy complex pair consisting of an aluminum atom replacing a silicon atom and an adjacent carbon vacancy $\left(\mathrm{Al}_{\mathrm{Si}}-\mathrm{V}_{\mathrm{C}}\right)$. The facts that the deep acceptor level $(0.58 \mathrm{eV})$ of yellow luminescence from our DAP recombination model in Fig. $3 \mathrm{~b}$ was more shallow than the deep boron level (0.63-0.74 eV) [3-5] and carbon layer appeared on the surface of the substrate after heating were consistent with Baranov et al. Furthermore, Kalabukhova et al. [16] explained a red luminescence center as a deep acceptor level at $0.8 \mathrm{eV}$ made by the complex of aluminum and an intrinsic defect. Because the peak near $1.95 \mathrm{eV}$ was observed when $\mathrm{Al}$ was injected in $6 \mathrm{H}-\mathrm{SiC}$. Their red luminescence was very similar with our PL configuration.

However, the luminescence could be attributed to the deep donor-shallow acceptor pair recombination (Fig. 3c) or to the deep level -substitution impurity level such as $\mathrm{N}_{\mathrm{Si}}, \mathrm{Al}_{\mathrm{C}}$. Regretfully, we could not find references to the above assumption except the theoretical calculations [17]. Thus, the red and yellow luminescence in figure 2 may be attributed to the DAP recombination between the aluminum deep acceptor related to the adjacent vacancies at the carbon site and nitrogen donor.

But all the data above can be explained in another way.

The $6 \mathrm{H}-\mathrm{SiC}$ crystals were heated under the conditions usually used for the $\mathrm{SiC}$ technology [18]. A $3 \mathrm{C}$-SiC single crystalline films have been grown on $6 \mathrm{H}-$ $\mathrm{SiC}$ substrates by heating in the presence of $\mathrm{SiC}, \mathrm{Si}$ vapor and at the gradient of temperature by modified Tairov's method.

Photoluminescence spectra of the heated crystal are shown on Fig. 4. Photoluminescence of the original (without heating) crystal is the same, but blue photoluminescence is more intensive. This spectrum is

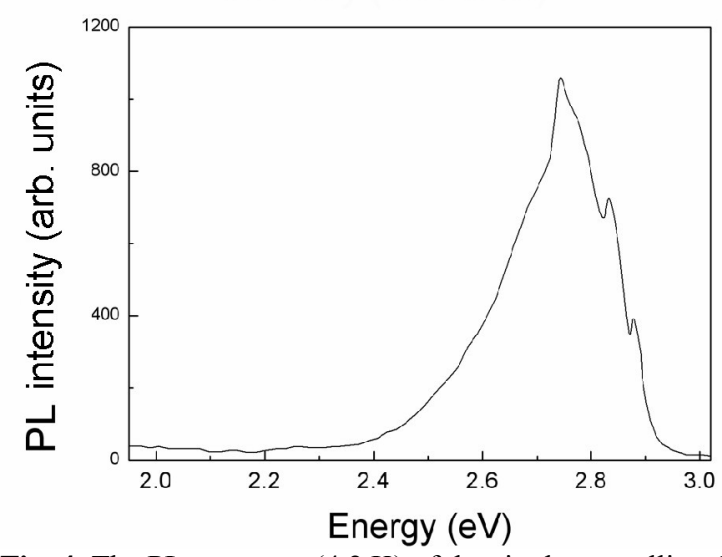

Fig. 4. The PL spectrum $(4.2 \mathrm{~K})$ of the single crystalline $6 \mathrm{H}$ $\mathrm{SiC}$ heated by Tairov's method. 
associated with the donor-acceptor pair N-Al recombination. From the Hall measurement (Fig. 5) it can be seen that the concentration of the noncompensated impurities $\left(N_{D}-N_{A}\right)$ has decreased (by two orders of magnitude). The ionization energy of shallow nitrogen remained the same as in the original crystal (Fig. 6), namely $0.08-0.10 \mathrm{eV}$. The ionization energy level of about $0.22 \mathrm{eV}$ appears due to the existence of some deformation. Free carriers mobility increases with the rise of the temperature as shown in Fig. 7.

This data clearly shows that there is a loss of carries from $6 \mathrm{H}-\mathrm{SiC}$. The EPR data gives evidence that the concentration of nitrogen is the same as in the original crystal and the quality of annealed $6 \mathrm{H}-\mathrm{SiC}$ is very high. At room temperature $\mathrm{Al}$ compensates $\mathrm{N}$, but EPR can not recognize this fact. This may be due to the fact that some of the nitrogen donors were compensated by the acceptors, which could be vacancies or complexes of the impurity atom-vacancy (intrinsic point defects).

A photoluminescence spectrum of another annealed crystal is shown in Fig. 8. This photoluminescence is very similar to the self-heated $\mathrm{SiC}$.

The photoluminescence spectra of $6 \mathrm{H}-\mathrm{SiC}$ with $3 \mathrm{C}$ $\mathrm{SiC}$ films on its surface is shown in Fig. 9 (curve 1), and the photoluminescence spectra of $3 \mathrm{C}-\mathrm{SiC}$ films on $6 \mathrm{H}-$ $\mathrm{SiC}$ (the mosaic crystal) is shown in Fig. 9 (curve 2).

Two main series (A and B) of maximums were observed at 2.12, 2.08, 2.05, 2.02, $1.95 \mathrm{eV}$ due to the electron transition from the conductive zone to the acceptor level of $\mathrm{Al}$ (series $\mathrm{A}$ ) and due to transitions of the electrons localized on the neutral donor to the acceptor (series B) [19-22].

From the Hall measurement it can be seen that free carriers concentration was about $10^{17} \mathrm{~cm}^{-3}$ and there is a loss of carriers. From the EPR measurement the concentration of nitrogen is about $3 \times 10^{18} \mathrm{~cm}^{-3}$ which is the same as in the original crystal. This may be due to the free carriers transfer from $6 \mathrm{H}-\mathrm{SiC}$ into the $3 \mathrm{C}$ stacking faults or due to the compensating process by created intrinsic defects.

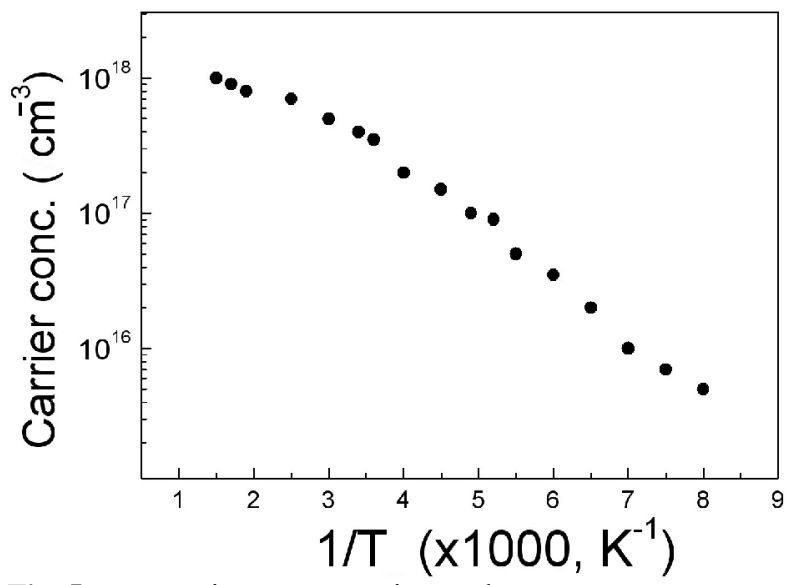

Fig. 5. Free carriers concentration vs the temperature.
The stacking faults (SFs) locally have a 3C stacking order. Because $3 \mathrm{C}-\mathrm{SiC}$ has the band gap which is lower than the $6 \mathrm{H}-\mathrm{SiC}$, there is a significant transfer of free electrons into the stacking faults. The loss of carriers from the $6 \mathrm{H}-\mathrm{SiC}$ matrix and the formation of multiple quantum-well-like regions of the $3 \mathrm{C}-\mathrm{SiC}$, lead to significant changes of the electrical properties (concentration of free carriers decreased by one/two order of magnitude) [23].

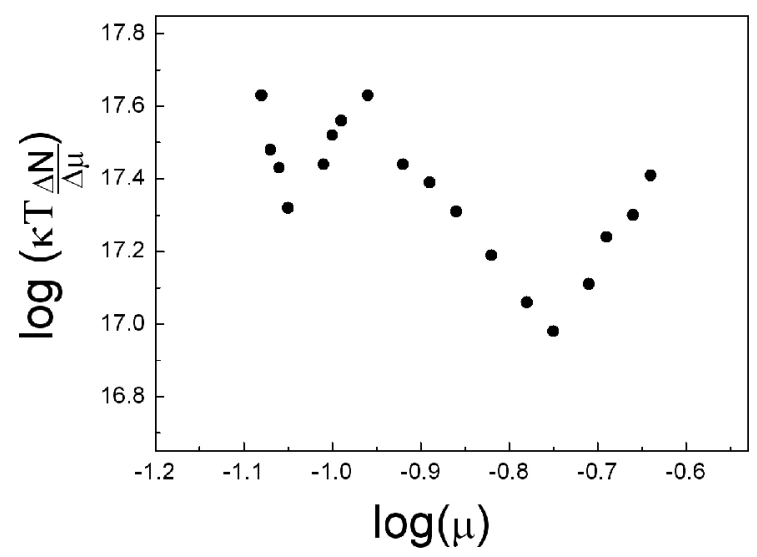

Fig. 6. Differential method of the ionization energy calculation according to Hofman. ( $\mu$ is the level of chemical potential).

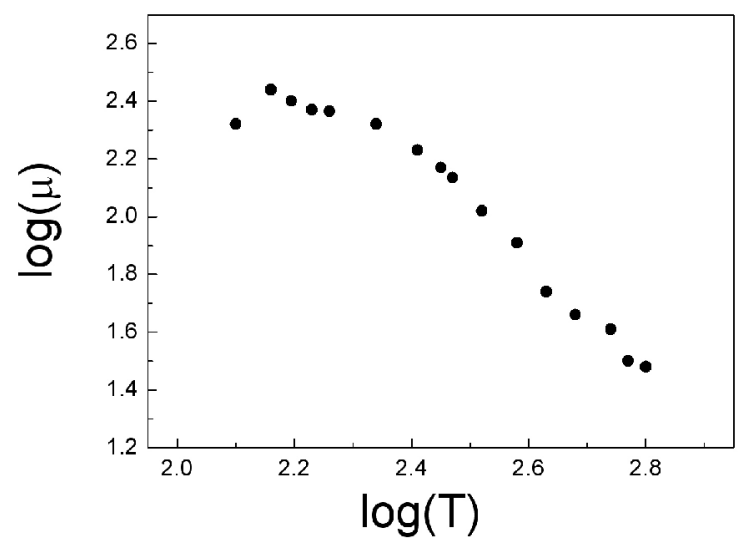

Fig. 7. Temperature dependence of the free carrier mobility.

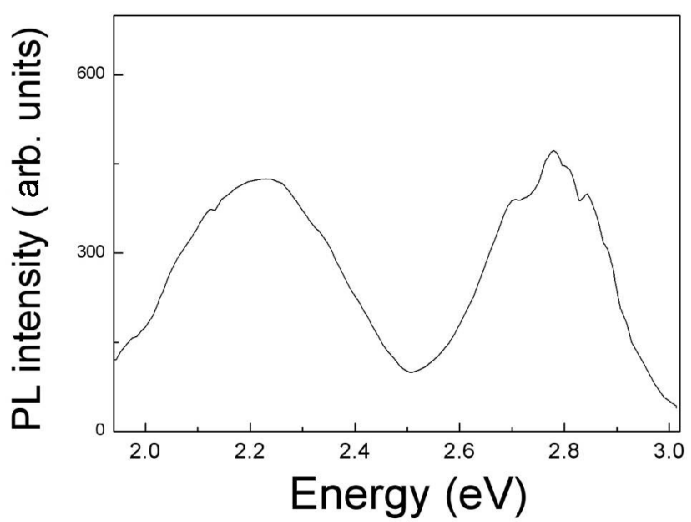

Fig. 8. The PL spectrum $(4.2 \mathrm{~K})$ for the single crystalline $6 \mathrm{H}-$ $\mathrm{SiC}$ heated in vacuum (in graphite furniture). 


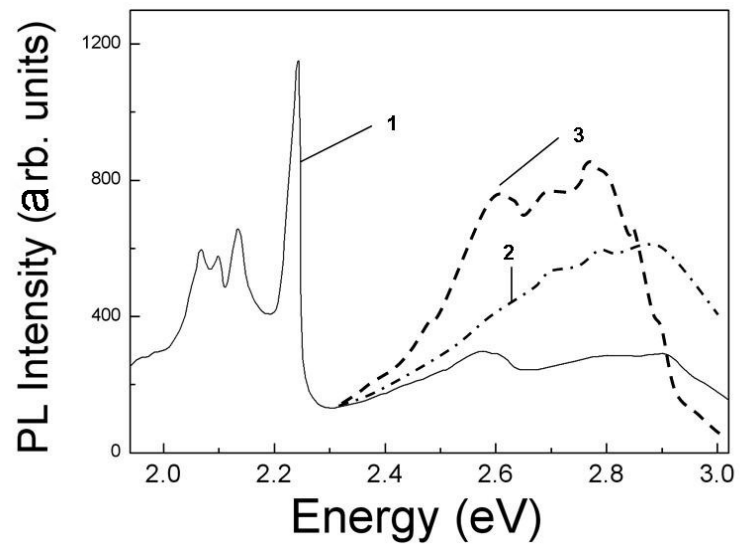

Fig. 9. The PL spectrum (4.2 K) of $3 \mathrm{C}-\mathrm{SiC}$ single crystalline film on the $6 \mathrm{H}-\mathrm{SiC}$ substrate (1), mosaic $3 \mathrm{C}-6 \mathrm{H}-\mathrm{SiC}$ crystal (2), mixed 3C-SiC-6H-SiC films (3).

The stacking faults create a quantum-well-like local potential. This level acts as a radiative recombination center responsible for the SFs luminescence.

From the comparison of the photoluminescence spectra it is clear that Al-N DAP recombination in $6 \mathrm{H}-$ $\mathrm{SiC}$ and in 3C-SiC takes place, and some area of disorder in the crystal structures is responsible for the luminescence in $2.4-2.5 \mathrm{eV}$ region.

We can assume that the processes of creation of the intrinsic defects occur in the annealed crystals and the nucleation of partial dislocation takes place during selfheating by current (the same as during the high current operation). The motion of partial dislocations and dislocation dissociation forms stacking faults. The $3 \mathrm{C}$ $\mathrm{SiC}$ stacking order forms quantum-well-like regions of the $3 \mathrm{C}-\mathrm{SiC}$ in the $6 \mathrm{H}-\mathrm{SiC}$ crystal. The formation of the quantum-well-like regions of the $3 \mathrm{C}-\mathrm{SiC}$ leads to the free carriers loss and is responsible for the photoluminescence in $2.3-2.5 \mathrm{eV}$ region (area of disorder). Photoluminescence in $1.8-2.2 \mathrm{eV}$ is associated with the donor acceptor pair $\mathrm{N}-\mathrm{Al}$ recombination in $3 \mathrm{C}$ $\mathrm{SiC}$ region (maximum at 2.12, 2.05, 2.00, $1.95 \mathrm{eV}$ ).

\section{Conclusions}

We annealed $6 \mathrm{H}-\mathrm{SiC}$ substrates by current with no boron injection at the temperatures of 1350 and $1500{ }^{\circ} \mathrm{C}$ in vacuum. After heating black carbon layers were observed on the substrates. The carbon layers on the substrates indicated the formation of the vacancies at the carbon sites. The PL spectrum of the heated $6 \mathrm{H}-\mathrm{SiC}$ recorded red and yellow luminescence.

We succeeded in creating the bright red and yellow luminescence center involving the deep aluminum acceptor. The red and yellow luminescence may be attributed to the DAP recombination involving the aluminum deep acceptor related with the adjacent vacancies at the carbon sites and nitrogen shallow donor.
Also another model is possible. The processes of intrinsic defects creation occur in annealed crystals and they create partial dislocations. The nucleation of the partial dislocations takes place during self-heating by current in the same way as during the high current operation. The partial dislocation's movement and dissociation form the stacking faults. The 3C-SiC stacking order forms the quantum-well-like regions of the $3 \mathrm{C}-\mathrm{SiC}$ in the $6 \mathrm{H}-\mathrm{SiC}$ crystal. The formation of the quantum-well-like regions of the $3 \mathrm{C}-\mathrm{SiC}$ leads to the loss of free carriers and responsible for the photoluminescence in 2.3-2.5 eV (area of disorder). Photoluminescence in $1.8-2.2 \mathrm{eV}$ region can be associated with the donor acceptor pair N-Al recombination in $3 \mathrm{C}-\mathrm{SiC}$ region.

\section{References}

1. S. Soloviev and D. Cherednichenko, Y. Gao, A. Grekov et al., Forward voltage drop degradation in diffused $\mathrm{SiC}$ p-i-n diodes // J. Appl. Phys. 95(8) (2004).

2. P.G. Baranov, E.N. Mokhov // Inst. Phys. Conf. Ser. 142, p. 293 (1996).

3. W. Suttrop, G. Pensl, and P. Lanig // Appl. Phys. A 51, p. 231 (1990).

4. M. Soueidan, G. Ferro, B. Nsouli et al., Boron doping vapor-liquid-solid growth of homoepitaxial 4H-SiC layers // Material Science Forum 556-557, p. 65-68 (2007).

5. R.P. Devaty and W.J. Choyke // Phys. status solidi (a) 162, p. 5 (1997).

6. M. Ikeda, H. Matsunami, and T. Tanaka // Phys. Rev. B 22, p. 2842 (1980).

7. M.M. Anikin, A.A. Lebedev, A.L. Syrkin, and A.V. Suvorov // Sov. Phys. Semicond. 19, p. 69 (1985).

8. M.S. Mazzola, S.E. Saddow, P. Neudeck, V.K. Lakdawala, and S. We // Appl. Phys. Lett. 64, p. 2730 (1994).

9. M.S. Mazzola, S.E. Saddow, and C.W. Tipton // Inst. Phys. Conf. Ser. 142, p. 473 (1996).

10. H. Kuwabara and S. Yamada // Phys. status solidi (a) 30, p. 739 (1975).

11. T. Daliver, G. Pensl, H. Matsumami, T. Kimoto, W.J. Choyke, A. Schöner, and N. Nordell // Phys. status solidi (a) 162, p. 199 (1997).

12. W.J. Choyke and Lyle Patrick // Phys. Rev. 127, p. 1868 (1962).

13. V.I. Sankin, G.B. Dubrovskii // Sov. Phys. Solid State 17, p. 1193 (1975).

14. L. Patrick // Phys. Rev. 180, p. 794 (1969).

15. P.G. Baranov, I.V. Ilyin and E.N. Mokhov // Solid State Communs. 100, p. 371 (1996).

16. E.N. Kalabukhova, S.N. Lukin, E.N. Mokhov, J. Reinke, S. Greulich-Weber and J.-M. Spaeth // Inst. Phys. Conf. Ser. 142, p. 333 (1996).

17. A. Fukumoto // Phys. status solidi (b) 202, p. 125 (1997). 
18. S.I. Vlaskina, D.H. Shin, $6 \mathrm{H}$ to $3 \mathrm{C}$ polytype transformation in silicon carbide // Jpn. J. Appl. Phys. Part 2, 38, No.1A/B, p. L27-29 (1999).

19. G. Zanmarchi, Luminescence of the aluminium centre in cubic SiC // J. Phys. Chem. Solids 29, No.10, p. 1727-1736 (1968).

20. J.A. Freitas, S.G. Bishop, P.E. Nordguist, M.L. Gipe, Donor bonding energies determined from temperature dependence of photoluminescence spectra in undoped and aluminium doped beta SiC films // Appl. Phys. Lett. 52, No. 20, p. $1695-1697$ (1988).
21. J.A. Freitas, Jr., Photoluminescence spectra of SiC polytypes, In: Properties of Silicon Carbide, Ed. G.L. Harris // EMIS Datareviews Series No. 13, p. 29-41(1995).

22. A.A. Lebedev, V.V. Zelenin, P.L. Abramov et al., Growth and study of thick 3C-SiC epitaxial layers produced by epitaxy on 6Y-SiC substrates // Material Science Forum 556-557, p. 175-178 (2007).

23. O.J. Glembocki, M. Skowronski, S.M. Prokes, D.K. Gaskill and J.D. Caldwell, Observation of free carrier redistribution resulting from stacking fault formation in annealed 4H-SiC // Material Science Forum 527-529, p. 347-350 (2006). 